\title{
Conceptualizing Intellectual Attention
}

Mark Fortney

Published in Theory \& Psychology, 2019.

Approximately 7000 words.

Penultimate draft. Please refer to published draft for citation.

https://journals.sagepub.com/doi/10.1177/0959354319853632

\begin{abstract}
:
Remembering that there's a difference between intellectual and perceptual attention can help us avoid miscommunication due to meaning different things by the same terms, which has been a particular problem during the last hundred years or so of the study of attention. I demonstrate this through analyzing in depth one such miscommunication that occurred in a philosophical criticism of the influential psychological text, Inattentional Blindness.

But after making the distinction between perceptual attention and intellectual attention, and after making an effort to keep this distinction in mind, we're still faced with the problem of specifying what makes intellectual attention distinct from perceptual attention. So in the second half of this article, I discuss the range proposals about how to understand intellectual attention that are present in the literature, and the problems with them. I do this with the aim of stimulating further discussion about how best to conceptualize intellectual attention, although I do not settle that further question within this paper.
\end{abstract}




\section{Introduction}

William James, in his seminal Principles of Psychology, distinguished perceptual attention and intellectual attention with reference to their objects. He said that perceptual attention can be directed at "sensorial objects", by which he means "object that an agent is perceiving, or could be perceiving", and that intellectual attention can be directed at "ideal or represented objects” (James 1890 p. 416). More recently, many psychologists have started to use the term "cognitive" or "reflective" rather than "intellectual", but otherwise seem to be trying to follow in James's footsteps rather than marking a new distinction.1. The intellectual variety of attention continues to be studied up until the present day (see, e.g., Johnson et al 2015). Within this article I'll just use the term "intellectual attention" rather than using the full list of terms every time I refer to the phenomenon in question.

Remembering that there's a difference between intellectual and perceptual attention can help us avoid miscommunication due to meaning different things by the same terms, which has been a particular problem during the last hundred years or so of the study of attention. I demonstrate this through analyzing in depth one such miscommunication that occurred in a philosophical criticism of the influential psychological text, Inattentional Blindness.

But after making the distinction between perceptual attention and intellectual attention, and after making an effort to keep this distinction in mind, we're still faced with the problem of specifying what makes intellectual attention distinct from perceptual attention. So in the second half of this article, I discuss the range proposals about how to understand intellectual attention that are present in the literature, and the problems with them. I do not answer the question of how best to conceptualize intellectual attention through this summary and critique, but instead aim to help stimulate discussion amongst scientists studying this variety of attention. In the interdisciplinary spirit of cognitive science, the range of proposals about how to understand intellectual attention that I discuss

1 Recently, "internal" and "reflective" have become more popular terms than "intellectual", but the psychologists using these terms say explicitly that they intend to mark the same distinction that James did (see, e.g. Chun, Golomb, and Turk-Browne 2011 p. 77 and Backer and Alain 2014 p. 439). 
are written by both philosophers and psychologists.

Before we begin, here is a note about the methodology of this paper. This paper takes, as its data, facts about the ways we talk about attention in ordinary language, and facts about the ways various psychologists and philosophers define attention, and uses these data to come to a conclusion about how various definitions of attention are wanting. There is a temptation to ask, "What laboratory-style test could help us determine which of these definitions is the best one?", but this temptation should be avoided because coming up with the requisite test is methodologically impossible.

The issue here is how to define attention before we engage in any sort of empirical tests involving attention. There are in fact no experiments that have ever been conducted into the question of how to define attention, and no such experiments ever will be conducted. Instead, what experimentalists universally do is assume a definition of attention and then try to discover the properties of attention. This paper examines and interrogates those assumptions, with the aim of stimulating more foundational discussions about attention.

\section{Miscommunicating about attention: a case study}

Distinguishing between perceptual attention and intellectual attention gives us additional resources to help us understand when theorists studying attention are actually miscommunicating with each other rather than genuinely disagreeing with each other. Expanding our resources to deal with that sort of problem is useful for any area in philosophy, but especially critical for the study of attention. Psychologists and philosophers have argued that miscommunication due to unacknowledged, different ways of understanding "attention" has been a particular problem with the study of attention for almost as long as attention has been an object of psychological and philosophical inquiry (see e.g. Anderson 2011).

To demonstrate how just distinguishing between perceptual and intellectual attention can help us resolve this kind of miscommunication, I will now analyze and resolve an apparent disagreement between Christopher Mole (2008) and Arien Mack \& Irvin Rock (1998). Mole says that Mack \& Rock argue for the thesis that we can perceptually attend to 
something without being perceptually conscious of it. But I will argue that in the passages Mole cites, Mack \& Rock argue for a much less contentious thesis: the thesis that we can intellectually attend to something without being perceptually conscious of it. So their dispute is on that could have been avoided, had the concept of intellectual attention been readier to hand in Mole's interpretation of Mack \& Rock.

Note that my argument in this section is purely interpretative: I don't mean to say that Mack \& Rock are right about the relationship between attention and consciousness, and instead just intend to establish one limited conclusion: that on one occasion when they were making an argument about intellectual attention, Mole believed that they were making an argument about perceptual attention instead.2

\subsection{Introducing the miscommunication}

This miscommunication occurs in his article "Attention and Consciousness" (2008), where Mole addresses arguments against what he calls the common-sense picture of the relationship between perceptual attention and perceptual consciousness. This commonsense picture, Mole argues, is motivated by reflections on our everyday experiences. Here is how Mole puts those reflections:

In our everyday encounter with the mental we take the relationship between attention and consciousness to be a close one. We catch someone's attention as a way to influence what he is conscious of, and it is by introducing something into his field of consciousness that we catch his attention...

The fact that we expect attention and consciousness to behave in these ways is made intelligible if we understand common-sense psychology

2 Note, however, that I do not mean to take issue with Mole's broader project, in which he correctly interprets other arguments of Mack \& Rock's arguments in favour of more restricted theses, and to fruitfully engage with those arguments. My goal in this article is just to look at why one of his arguments rests in a misinterpretation in order to provide some evidence for the claim that the distinction between perceptual and intellectual attention can help theorists avoid miscommunicating with each other. 
to treat paying attention to something as a way of being conscious of that thing: a way that locates the thing attended in the foreground of experience. According to common-sense psychology, then, attention requires consciousness (Mole 2008 pp. 88-89).

Mole's claim attention causes something to be located in the "foreground" of conscious experience is worth elaborating on a bit. The claim in question is the thesis that consciously attending an object causes our experience of that object to become foregrounded (or more vivid, or more central) in our fields of consciousness. Mole (2008) argues that this claim is a part of the folk theory of attention and consciousness.

Here's an explanation of what it means for something to be made more foregrounded, or more vivid, or more central in consciousness. Consider figure below:

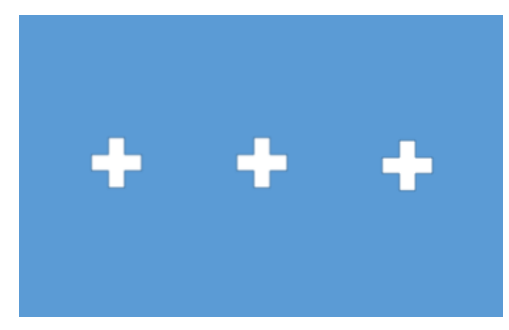

There are (at least) two different ways to see this image. While directing your gaze at the centre cross, you can focus your visual attention on the cross on the left, in which case the cross on left seems to be in the foreground of your consciousness and cross on the right seems to be in the background of your consciousness. Alternatively, while directing your gaze at the centre cross, you can focus your visual attention on the cross on the right, in which case the cross on the right is in the foreground of your consciousness and the cross on the left is in the background of your consciousness. Mole's claim is that, according to the common sense view of visual attention and visual consciousness, shifts in visual attention cause changes in what is in the foreground of visual consciousness. 


\subsection{Why my interpretation of Mack \& Rock is more charitable than Mole's}

According to Mole, some psychologists have argued that certain results threaten the common-sense picture of the relationship between visual attention and visual consciousness (see, e.g., Mack \& Rock 1998, Kentridge \& Heywood 2001, and Koch \& Tsuchiya 2007).3 Some

of them have argued that attention is psychologically necessary for consciousness, while others have argued that consciousness is not psychologically necessary for attention. Most of these psychologists' arguments are based on surprising data that they have collected, but a few are based on reflection on ordinary experience.

According to Mole, Mack \& Rock reject the claim that perceptual consciousness of an object is required for us to perceptually attend to that object, and moreover they argue that such a claim is not a part of the common-sense picture of the relationship between attention and consciousness (2008 p. 98).4 This is the passage from Mack \& Rock that Mole uses to justify that claim:

Unfortunately, although the proposal that conscious perception and attention refer to identical processes has the advantage of simplicity, it is discredited on several grounds. First, it would appear to lead to the false conclusion that there can be no attention without [conscious] perception. This conclusion seems false on both experiential and empirical grounds. (Mack \& Rock 1998 p. 245).

I am interested just in the experiential grounds that Mack \& Rock cite as counterexamples to the thesis that there is no attention without conscious perception. The experiences that Mack \& Rock cite as counterexamples to this thesis are "looking for

3 Mole has, in fact, changed his view about whether this line of research undermines the common sense view. In "Attention to Unseen Objects" (2014), he argues that work published after his paper "Attention and Consciousness" (2008) has actually managed to undermine the common-sense view.

4 Mole does not put the thesis quite this way: he says that they reject the claim that consciousness is required for attention (2008 p. 98). But earlier he states that what he means by that is the claim that consciousness of an object is required for attention to that same object (2008 p. 89). 
something or keenly awaiting its appearance in the absence of perceiving it" (1998 p. 245).

Mole agrees with the observation that we can keenly await something's appearance without perceiving it, but says that the observation "doesn't make the point that [Mack \& Rock] think it makes", because "although one can't attend to just any arbitrary absence, one can, for example, give full attention to a radar screen, waiting for a pip even when no pip comes" (2008 p. 98). Mack \& Rock's approach, Moles goes on to argue, "confuses the perception of absence with the absence of perception" (2008 p. 98). Thus, Mole believes that Mack \& Rock believe that a subject's looking for something or keenly awaiting its appearance are activities that involve the subject's perceptual attention to, but no perceptual consciousness of, the objects that they are looking for or awaiting.

As Mole points out, such a view is mistaken. Keenly waiting for a pip to show up on a radar plausibly just involves perceptually attending to and being perceptually conscious of the radar screen, and then - only after the pip appears - perceiving the pip and perceptually attending to it. On Mole's interpretation, then, Mack \& Rock's argument fails. Moreover, their argument fails very obviously. But I think that their argument fails so obviously that it should be puzzling to us that Mack \& Rock thought of the argument at all - on Mole's interpretation of their argument, anyways.

The distinction between perceptual and intellectual attention, however, puts us in a position to interpret Mack \& Rock differently. Mole interpreted Mack \& Rock as making the following argument:

(1) People with ordinary vision can look for something, and thereby perceptually attend to it, without consciously perceiving it.

(2) Therefore, people with ordinary vision can perceptually attend to something without consciously perceiving it.

But with the distinction between perceptual and intellectual in hand, we may instead interpret Mack \& Rock as making the following crucially different argument:

(1) People with ordinary vision can look for something, and thereby 
intellectually attend to it, without consciously perceiving it.

(2) Therefore, people with ordinary vision can intellectually attend to something without consciously perceiving it.

My interpretation gives us the resources to tell the same story about Mack \& Rock's discussion of waiting for a pip to appear on a screen: we could say that they thought that we can think intently about the pip that is about to appear, and thereby intellectually attend to it without consciously perceiving it.

As Mack \& Rock suggest, reflection on examples like the ones they mentioned certainly suggests that their thesis is true. Thinking intently about an object - so intently that we call the thought "attentive thought" - can obviously happen when the object is not in perceptual range or perceptible at all. This kind of thought can sometimes impair perception, as Aristotle notes in On the Sense and the Sensible: “.... persons do not perceive what is brought before their eyes, if they are in deep thought, or in a fright, or listening to some loud noise" (Sens. 447a14-16; citation from Barnes 1984). The day to day experience of intense thought interfering with perception that Aristotle notes has even been replicated in the laboratory: see Fougnie and Marois (2007) for evidence that mentally alphabetizing a list of letters can cause inattentional blindness, and that merely remembering the list without making an effort to order it does not cause inattentional blindness.

On my interpretation, then, Mack \& Rock's argument is grounded in common-sense assumptions about conscious thought and perception that have been empirically corroborated. So on my view, their argument actually makes sense and does not fail as quickly and obviously as it does on the interpretation offered by Mole. For reasons of charity, therefore, we ought to strongly prefer my interpretation of Mack \& Rock to Mole's interpretation of Mack \& Rock.5

5 My interpretive strategy, like Mole's, involves looking to Mack \& Rock's use of the word "attention" to figure out what "attention" means for them. The explicit definition they give in the introduction to their book is clearly inconsistent with the way they use the word throughout much of the rest of the book (see Mole 2008 pp. 93-94 for discussion). 
Moreover, reasons of charity are not the only reasons to prefer my interpretation. Mack \& Rock actually raise two more arguments based on ordinary experiences to establish the point that we can attend to something without being conscious of it. The way that Mack \& Rock present these two arguments make it clear that the kind of attention they have in mind is intellectual and not perceptual. I'll discuss these arguments in turn.

\subsection{Additional textual evidence for my view}

In their second additional argument, which makes the point most clearly, Mack \& Rock say that we can attend to non-perceptible objects, like "ideas" and "feelings", without perceiving them, and that this observation also problematizes the thesis that there is no attention without perception (1998 p. 246). So they must mean to say that we can intellectually attend to ideas and feelings without consciously perceiving them - they couldn't have meant to say that we can't consciously perceive ideas but that we can perceptually attend to ideas. It might be possible to conceive of a subject rigged up to have such a combination of psychological capacities, but Mack \& Rock are clearly talking about the capacities of normal humans.

In their third additional argument, Mack \& Rock say that when we are tasked with reacting when a pip appears on a screen, but no pip ever appears, we "attend without perceiving", and that this observation also problematizes the thesis that there is no attention without perception (1998 p. 485). This argument is a bit more puzzling than the other arguments-as Mole correctly points out, carefully watching screens seems to involve consciously perceiving the screens and perceptually attending to the screens. But we can interpret Mack \& Rock as meaning that we intellectually attend to the pip without perceiving the pip because, in this case, carefully watching the screen involves perceiving and perceptually attending to the screen and intellectually attending to the pip that is yet to arrive without consciously perceiving the pip.

Of course, this line of argument might fail: there is an interesting empirical question to be asked about whether the swift way we respond to pips when we are watching screens carefully can be fully explained by our being vigilant while waiting for the pip to appear, or 
whether we also need to posit that intellectual attention plays a role in causing our speedy reactions to the pips. Moreover, there are several versions of that latter hypothesis that would need to be distinguished: e.g. whether that intellectual attention is directed at a nonexistent pip, or whether that intellectual attention is directed at pips in general.6 But these potential problems pertain to whether Mack \& Rock were right in making this additional argument, and my interest here is just in the proper interpretation of Mack \& Rock. Having the concept of intellectual attention ready to hand is crucial for interpreting their arguments about attention and consciousness correctly, and thereby crucial for addressing the miscommunication between Mole and Mack \& Rock.

As I mentioned above, after making the distinction between perceptual attention and intellectual attention, and after making an effort to keep this distinction in mind, we're still faced with the problem of how to properly define these varieties of attention. So now I will discuss a range of proposals about how to do so.

The question of how to define intellectual attention is rarely explicitly taken up in philosophy and psychology. In the second half of this paper, I'll discuss three recent proposals, two from philosophy and one from psychology, all made in apparent isolation from each other. I raise problems for all the proposals, with the aim unifying these disparate discussions and also stimulating further discussions about how to conceptualize intellectual attention." I leave the task of motivating an alternative and superior definition for another day, as it's a substantive enough task to unify and criticize the recent extant discussions of intellectual attention.

6 The suggestion that it is possible to intellectually attend to a pip that doesn't exist yet also raises the question of whether we can have a singular thought about an object that doesn't exist yet, which we do not need to resolve here - see Recanati 2012 p. 164 for discussion. Again, our focus here is on what Mack \& Rock believe rather than the plausibility of what they believe. 


\section{Intellectual attention as "thinking"}

Daniel Stoljar, in his paper "The Argument from Diaphanousness" (2004), argues that intellectual attention to an object just is thinking about that object. $7 \mathrm{He}$ argues that we should accept his definition just because it makes sense of the following two ordinary uses of the word "attention":

(1) 'Let us now attend to the second flaw of the argument.'

(2) 'The program made us attend even more than we had before to the effects of salination on the nation's rivers.'

As Stoljar observes, "attend to", in the above two sentences, might just mean 'think about' (2004 p. 374). Making sense of these ordinary-language claims does not obviously require positing that intellectual attention to an object is anything over and above thought about an object.

Should our theory of attention really be driven by linguistic considerations such as these? Perhaps not - I'll return to this presumption of Stoljar's below. But I'll argue that even if our theory should be driven by such considerations, Stoljar's theory should not be accepted. Consider these two examples of ordinary thought and talk about attention.

(A) ...[I]n my opinion a man has no manly motive or sustainment in his own breast for facing dangers, unless he has well considered what they are... On this principle I have so attentively considered (regarding it as my duty) all the hazards I have ever been able to think of, in the ordinary way of storm, shipwreck, and fire at sea... (Dickens 1856)

\footnotetext{
${ }_{7}$ Stoljar calls intellectual attention "cognitive attention", but I will use my own terminology in this article to
} keep things simple. 
(B) But armed uprising is a special form of political struggle, one subject to special laws to which attentive thought must be given. (Lenin 1917)

According to case (A), the speaker does not just consider hazards - the speaker attentively considers hazards. Case (B), similarly, refers to attentive thought about armed uprisings not mere thought about them. So what (A) and (B) show us is that the folk notion of thought allows for (at least) two modes of thought: the attentive way of thinking and the inattentive way of thinking. On such a view, when we think about an object we do sometimes think attentively - but we might just as readily engage in inattentive thought about the object. Consider, to illustrate this point, Christopher Mole's description of a devoted but tired scholar:

“... the devoted scholar who has spent too long at his desk. His reading of the book before him is prompted by genuine interest, but having spent the whole day trying to ignore the pangs of hunger, the children in the next room, and the radio that is playing downstairs, he is no longer able to concentrate. His reading is prompted by interest, but it is not attentive." (Mole 2011 pp. 48-49).

Mole's description of the case is apt: there is an inattentive mode of thought as well as an attentive mode of thought, and the scholar is failing to engage in the attentive mode of thought. What all this shows is that Stoljar's definition of intellectual attention is at odds with the folk notions of thought and attention. But his claim was that we should accept his definition of intellectual attention just because it was the folk notion of intellectual attention! So even if we grant the (contentious) assumption that we should accept a definition of intellectual attention just because it was the folk notion of intellectual attention, Stoljar's 
argument is unsuccessful. There are simply more ordinary uses of "attend" than he considers.8

Lastly, a remark about that contentious assumption made by Stoljar, according to which considerations about ordinary thought and talk about attention should guide our theory of attention: while I do not think that our theory of attention must, ultimately, be consistent with every pronouncement of ordinary thought and talked about attention, I do think that ordinary thought and talk about attention constitute the starting point for our theorizing. And coming up with a definition of attention is one of the first things we do after we start. But regardless of whether this way of thinking about the relationship between ordinary and theoretical talk about attention is ultimately tenable, Stoljar's proposal about how to understand intellectual attention should be rejected.

\section{Intellectual attention as "conscious thinking"}

Ian Phillips (2012), following Michael Martin (1997), argues that what distinguishes intellectual attention from perceptual attention is that the former simply is our stream of conscious thought, while the latter is a modification of our streams of conscious perception.9 This way of distinguishing between perceptual attention and intellectual attention can be used to generate a definition of intellectual attention - "conscious thought".10

8 I take the folk notions of thought and attention to be the set of platitudes about the causal roles of thought and attention that we would all endorse rather than to a set of psychological capacities - see Stich and Nichols (2003) for a discussion of this distinction.

9 Phillips calls intellectual attention "internal attention"; I'll use my own terminology in this article to keep things simple. Martin just uses the word "attention", but it is clear from the context that he is discussing intellectual attention.

10 Throughout, I discuss phenomenal consciousness rather than what Block (1995) has called "access consciousness". Note also that to say that there is conscious thought is not to make the presumption that there is a sui generis phenomenology of thought (see Pitt 2004 for a defense of such a view and Tye \& Wright 2011 for a criticism of such a view). It is just to say that sometimes there is something it is like to think. 
This definition faces a methodological problem. Martin's and Phillips's definition of intellectual attention puts us in a poor position to begin a combination of a "conceptual inquiry" and a "descriptive inquiry" into the nature of intellectual attention - what I will call a "blended inquiry".11 First I'll discuss the distinction between conceptual inquiries and descriptive inquiries, and then I'll explain why their definition of intellectual attention puts us in a poor position to begin such a blended inquiry into the concept of intellectual attention.

First, we can distinguish between two kinds of conceptual inquiries. In the first kind, we try to figure out what the folk think the analysis of a concept is. In the second kind, an individual tries to figure out what her own analysis of the concept should be. In the former kind of conceptual inquiry, we try to come to understand how a given population of people understand a concept, while in the latter kind, we do things like use intuitions that an individual has about cases to guide us in forming our analysis. For a deeper discussion of this distinction between these two kinds of conceptual inquiry see, e.g., Paul Grice's discussion of the distinction between what he calls "Oxonian" and "Athenian" dialectic in his book Studies in the Ways of Words (1989, pp. 380-381). Unsurprisingly, "Oxonian" dialectic refers to the first kind of conceptual inquiry, "Athenian" the second.

Note that Stoljar's inquiry into the concept of intellectual attention was something like a very quick conceptual inquiry of the first kind. However, as I have already shown, a more careful conceptual inquiry of the first kind does not actually yield his definition of intellectual attention. The folk analysis of 'intellectual attention' must be more complex than Stoljar thinks it is.

Descriptive inquiries, by contrast, are inquiries that involve empirical investigation. Rather than making the analysis of a concept more complete through the methods we use to perform conceptual inquiries (e.g. reflective equilibrium), in a descriptive inquiry we make our analysis more complete by making empirical discoveries. The empirical discoveries in

11 See Haslanger (2004) for this distinction between kinds of inquiries and a different application of the distinction. 
question would, of course, be discoveries about something other than what the folk think about the concept: otherwise we would be performing an Oxonian conceptual inquiry.

The successes of cognitive science have shown that it is fruitful to study mental processes using an interdisciplinary methodology. So our investigation of intellectual attention should be informed (at least!) by both philosophy and psychology. Using the terms I have just introduced above, one might say that our inquiry into intellectual attention should be partly descriptive, because psychologists deepen our understanding of concepts by making empirical discoveries, and partly conceptual, because philosophers engage in conceptual inquiries (not to say that this is all philosophers do - philosophy admits of a wide variety of methodologies). The definition of intellectual attention that we adopt should, accordingly, be one that is well suited to being the starting point for such a blended inquiry into the concept of intellectual attention.

What makes a definition well suited to being the starting point for such an inquiry? Potentially many properties of the definition, but there are just two properties that I will keep in mind in this article. First, such a definition should be thick enough to allow us to properly get a grip on the phenomenon of intellectual attention - i.e., a definition that puts us in a position to identify the phenomenon in the world and to have substantive debates about its nature. Second, such a definition should also be thin enough to leave room for us to deepen our understanding of the phenomenon through engaging in philosophical and psychological work.

A problem with accepting Martin's and Phillips's definition of intellectual attention is that it appears to close off the investigation of an apparently substantive question. To use the terminology I just introduced, their definition is too thick. Consider the question of whether there could be such a thing as unconscious intellectual attention. Phillips's and Martin's definition of intellectual attention rules out the investigation of this question, because according to their definition attention - both perceptual and intellectual - is always conscious. But there is currently a substantive debate about whether there can be unconscious attention, or whether attention is always conscious: see e.g., Koch and Tsuchiya 
(2007), Kentridge (2011), Norman, Heywood, \& Kentridge (2013) and Mole (2014) for arguments that there is unconscious attention, and Mole (2008), Smithies (2011) Watzl (2011) for arguments that there is only conscious attention. 12 The mere existence of this dispute is compelling evidence that the question of whether there can be non-conscious intellectual attention should not be settled by our definition of intellectual attention. It should, instead, be settled through philosophical and psychological inquiry.

\section{Two psychological conceptualizations of intellectual attention}

Marvin Chun, Nicholas Turk-Brown, and Julie Golomb (2009), have proposed two methods of distinguishing intellectual from perceptual attention (they use the terms "external" and "internal" rather than "perceptual" and "intellectual"). One is based on control - they say that perceptual attention can be uncontrolled, which is what makes it distinct from intellectual attention (p. 83)

However, mind-wandering is a counterexample to this way of distinguishing intellectual attention from perceptual attention, and a not insignificant one, given the significant amount of time we spend mind-wandering in the average day. Here is how Zachary Irving and Evan Thompson (2018) describe the phenomenon of mind-wandering:

Experientially, we all know mind-wandering when we see it. On the commute home, a programmer's thoughts drift away from the sights and sounds of the subway car. At first she imagines the chicken she is brining for dinner. She can almost taste the thyme and rosemary when, suddenly, a line of code pops into her head. She plays with the

\footnotetext{
12 The current debate has focused on perceptual attention and perceptual consciousness rather than intellectual attention and cognitive consciousness, but I think we should expect an analogous debate to emerge in the discussion of whether we can intellectually attend to something without being cognitively conscious of it.
} 
code for a while, and then, smiling, remembers a joke she heard today... and so on. (Irving and Thompson 2018 p. 88)

Mind-wandering is clearly something that involves intellectual attention, as the description above makes clear. The experience above is constituted, in part, by several shifts of intellectual attention, as the subject drifts from one line of thought to another. But the aptness of the term "drift" shows that these shifts in intellectual attention are best thought of as involuntary, and this clashes with the idea that we should conceptualize intellectual attention as the kind of attention which is mostly voluntary. There would be no genuine clash if these involuntary shifts of intellectual attention were relative rarities, of course. But as Irving (2016) notes, mind-wandering might occupy as many of half of our waking thoughts. So it is an ordinary kind of intellectual attention rather than a relative rarity.

Here is the second proposal that Chun, Turk-Brown, and Golomb make about defining intellectual attention:

External attention refers to the selection and modulation of sensory information, as it initially comes into the mind, generally in a modality-specific representation and often with episodic tags for spatial locations and points in time. This sensory information can be organized by features or into objects, which can themselves be targets of external attention. Another way to think of external attention is as perceptual attention. Internal attention refers to the selection and modulation of internally generated information, such as the contents of working memory, long-term memory, task sets, or response selection. (p. 77)

Defining intellectual attention as the attention that operates on internal "contents of selection" like thoughts and memories, rather than objects in the environment, has obvious appeal. When we think about examples like the above examples of mind-wandering, it's clear that intellectual attention can involve our attention shifting from one topic to another, one plan to another, and so on. 
However, our intellectual attention can also be targeted at the same sort of object as perceptual attention. When we make a careful judgment about an object we can see, we are engaging in a complicated process that involves both "internal" and "external" representations. By contrast, when we are wholly engaged in taking in the scene before us and not reflecting on it, we are engaged in a process which involves just "external" representations. But the judgment we make in cases like the former one seem like clear cases of intellectual attention. Intellectual attention, therefore, should not be defined in terms of its lack of involvement with proximal, modality specific representations. The core problem here is that Chun, Turk-Brown, and Golomb have identified a feature that is had by some examples of internal attention, but not all of them.

Here is another way that core problem manifests. Above, Chun, Turk-Brown, and Golomb suggest that what is distinctive about perceptual attention is that it deals with modality specific representations, while what is distinctive about intellectual attention is that it deals with amodal representations. But consider the imagination, and the attention we pay in imagining with particular focus or care. Imaginative representations are modality specific - visual, auditory, tactile, etc. - and not amodal. But the imagination is clearly an

intellectual rather than perceptual mode of engagement, and accordingly the attention we pay in imagining is intellectual rather than perceptual (When you imagined seeing a blue bird earlier in the day, it is not appropriate to say, "I perceived a blue bird earlier today."). It might well be that intellectual attention is often associated with amodal representations, but it is not an essential feature of intellectual attention. Again, the core problem here is that Chun, Turk-Brown, and Golomb have identified a feature that is had by some examples of intellectual attention, but not all of them.

\section{Conclusion}

With this article, I've tried to make two ideas clear: one, that it is important to keep the category of intellectual attention in mind, and two, that currently we are without a good definition of intellectual attention. However, my goal has expressly not been to foster skepticism about the prospects for developing a definition, or even to foster skepticism about current studies of intellectual attention. I think that term "intellectual attention" names a 
distinct phenomenon, which the scientific community will conceptualize more clearly as time goes on, and I think that many current studies of intellectual attention might manage to target the phenomenon, even without the best definition on hand. In gathering these remarks about intellectual attention and criticizing them, my goal has been to help stimulate discussion, and to move the scientific community towards a clearer and more complete way of conceptualizing intellectual attention.

\section{Works Cited}

Anderson B. (2011). There is no such thing as attention. Frontiers in Psychology, 2, 246. doi: 10.3389/fpsyg.2011.00246

Barnes, J. (1984). Complete Works of Aristotle. Princeton, NJ: Princeton University Press.

Backer, K., and Alain, C. (2013). Attention to memory: orienting attention to sound object representations. Psychological Research, 78(3), 439-452.

Block, N. (1995). On a Confusion about a Function of Consciousness. Behavioral and Brain Sciences, 18(2), 227-47.

Chun, M., Golomb, J., and Turk-Browne, N. (2011). "A taxonomy of external and internal attention”. Annual Review of Psychology, 62, 73-101.

Dickens, C. (1856). The Wreck of the Golden Mary. Retrieved from http://www.gutenberg.org/ebooks/9742

Fougnie, D. and Marois, R. (2007). Executive working memory load induces inattentional blindness. Psychonomic Bulletin and Review, 14(1), 142-147.

Grice, P. (1989). Studies in the Ways of Words. Cambridge, MA: Harvard University Press.

Haslanger, S. (2000). Gender and Race: (What) are they? (What) do we want them to be? Nous, 34(1), 31-55.

Irving, Z. (2016). Mind-wandering is unguided attention: accounting for the "purposeful" wanderer. Philosophical Studies, 173(2), 547-571.

Irving, Z., and Thompson, E. (2018). The philosophy of mind wandering. In K.C.R. Fox and K. Christoff (Eds.) The Oxford Handbook of Spontaneous Thought: Mind-Wandering (pp. 87-96). Oxford, UK: Oxford University Press.

James, W. (1890). The Principles of Psychology. Cambridge, MA: Harvard University Press. 
Jennings, C.D. (2012). The subject of attention. Synthese, 189(3), 535-554.

Johnson, M. R., McCarthy, G., Muller, K. A., Brudner, S. N., and Johnson, M. K. (2015). Electrophysiological correlates of refreshing: Event-related potentials associated with directing reflective attention to face, scene, or word presentations. Journal of Cognitive Neuroscience, 27(9), 1823-1839.

Kentridge, R. (2011). Attention without awareness: a brief review. In C. Mole, D. Smithies, and W. Wu (Eds), Attention: Philosophical and Psychological Essays (pp. 228-246). Oxford University Press.

Kentridge, R. and Heywood, C. A. (2001). Attention and alerting: Cognitive processes spared in blindsight. In by B. De Gelder E. H. F. De Haan, and C. A. Heywood (eds.), Out of Mind: Varieties of Unconscious Processes (pp. 163-184). Oxford University Press.

Koch, C., and Tsuchiya, N. (2007). Attention and consciousness: two distinct brain processes. Trends in Cognitive Science, 11(1), 16-22.

Lenin, V. (1917). "Advice of an onlooker". Retrieved from https://www.marxists.org/archive/lenin/works/1917/oct/08.htm

Mack, A. and Rock, I. (1998). Inattentional Blindness. Cambridge, MA: MIT Press.

Martin, M. (1997). "The shallows of the mind". Proceedings of the Aristotelian Society, Supplementary Volumes, 71, 55-98.

Mole, C. (2008). Attention and consciousness. Journal of Consciousness Studies, 4(15), 86104.

Mole, Christopher. (2011). Attention is Cognitive Unison: An Essay in Philosophical Psychology. Oxford, UK: Oxford University Press.

Mole, C. (2014). Attention to unseen objects" Journal of Consciousness Studies, 21(11-12), 41-56.

Norman, L., Heywood, C., and Kentridge, R. (2013). Object-cased attention without awareness. Psychological Science, 24(5), 836-843.

Phillips, I. (2012). Attention to the passage of time. Philosophical Perspectives, 26, 277-308.

Pitt, D. (2004). The phenomenology of cognition: or what is it like to think that $\mathrm{p}$ ? Philosophy and Phenomenological Research, 1, 1-36.

Recanati, F. (2012). Mental Files. Oxford University Press. 
Smithies, D. (2011). "Attention is rational-access consciousness". In C. Mole, D. Smithies, and W. Wu (eds.), Attention: Philosophical and Psychological Essays (pp. 247-273). Oxford University Press.

Stich, S. and Nichols, S. (2003). "Folk psychology," in S. Stich and T. Warfield (Eds.), The Blackwell Guide to Philosophy of Mind (pp. 325-255). Oxford, UK: Blackwell.

Stoljar, D. (2004). "The argument from diaphanousness". The Canadian Journal of Philosophy (Supplementary Volume), 30, 341-390

Tye, M., and Wright, B. (2011). "Is there a phenomenology of thought?" In T. Bayne and M. Montague (Eds.), Cognitive phenomenology (pp. 326-344). Oxford, UK: Oxford University Press.

Watzl, S. (2011). "Attention as structuring of the stream of consciousness". In C. Mole, D. Smithies, and W. Wu (Eds.), Attention: Philosophical and Psychological Essays (pp. 145173). Oxford, UK: Oxford University Press.

Watzl, S. (2017). Structuring Mind. Oxford, UK: Oxford University Press.

Wu, W. (2014). Attention. New York, NY: Routledge. 